American Journal of Agricultural and Biological Sciences 6 (4): 560-566, 2011

ISSN 1557-4989

(C) 2011 Science Publications

\title{
Identifying the Factors Affecting the Participation of Agricultural Cooperatives' Members
}

\author{
Bagher Arayesh \\ Department of Agriculture, Faculty of Agricultural Extension and Education, \\ Ilam Branch, Islamic Azad University, Ilam, Iran
}

\begin{abstract}
Problem statement: 40-year history of agricultural production cooperatives in the country shows that this type of exploitation system has faced many ups and downs during this period. First, despite the help and support by the government, the cooperative sector has not been able to play a major role in the development of the country and its share has not exceeded $3 \%$ of development program. The main aim of this study is identifying the factors affecting the participation of Shirvan-Chardavol township's agricultural cooperatives' members. Approach: This casual comparative applied research which uses survey method for data accumulation, is of Quasi-experimental research type because of impossibility of controlling the research variables. A researcher-made questionnair was used as the main tool for gathering data. The face and content validity of the questionnaire were confirmed by a group of university professors and cooperative experts; also the reliability of the questionnaire was confirmed through calculating the Kronbach alfa coefficient $(\mathrm{a}=0.80)$. Results: The statistical society of the research included 751 active members of Shirvan-Chardavol township's agricultural cooperatives, among which 260 people were selected for the study using classified proportional random sampling method and with the aid of Morgan sample-volume table. Data processing was performed using SPSS estatistial software, as well as descriptive estatistics (central and inferential indexes) and analytical estatistics (correlation coefficients and stepwise multiple regression analysis). Conclusion: The correlation coefficient results show that there is significant relationship between the variables like age, background history of membership in cooperatives, the members' agricultural land areas, annual income of the members, socio-cultural features, economical features, educational-extensional features, managerial factors, psychological features, political factors and communicational-informational factors from the one hand and the dependent variable of agricultural cooperatives' members' level of participation from the other. The multiple regression analysis results showed that variables like political, economic, managerial and social factors have positive effect on the dependent variable of agricultural cooperatives' members' participation, describing $65 \%$ of the changes of the mentioned dependent variable.
\end{abstract}

Key words: Farmer, agricultural production cooperative, active participation

\section{INTRODUCTION}

Pressures from the lack of adequate necessary resources, difficulty and inconsistency of trade conditions, the rising volume of foreign debts and finally the problem of repayments of loans, has caused the governments to seek solutions and to try other methods economic development. This is why the governments are trying to encourage participation of the people in the economic affairs and use cooperatives as a mechanism for accelerating the economic development of the villages. Agricultural production cooperatives are cooperation based exploitation systems in which the farmers produce agricultural crops through collective farming using integrated cultivation method meanwhile maintaining individual ownership. Nowadays the international community and conventions admit the relationship between the public potential and real stakeholders. Many previous experiences of the governments in different regions, especially in rural areas indicate that the noninvolvement of the people in processes of the plans has caused the villagers never feel they belong to the projects implemented. This has provided for failure of such projects in long-term (Arayesh and Hosseini, 2010). Cooperative companies due to giving their members active role and participation in all stages of establishment and development of its activities have been turned out to be known as distinguished and noble centers of contribution (Peterson, 2004). 40-year history of agricultural production cooperatives in the country shows that this type of exploitation system has faced many ups and downs during this period. First, despite the help and support by the government, the 
cooperative sector has not been able to play a major role in the development of the country and its share has not exceeded 3\% of development program (Arayesh, 2011). Second, the cooperative movement in all successful countries is considered a popular movement, while in Iran the government has been the pioneer of the movement. This can cause people to doubt the noble ideas of taking part in cooperatives and imagine it as state or quasi-governmental organization with particular political desires. In such circumstances the members do not feel they belong to cooperatives and do not make much effort to achieve its goals (Mousaei and Arayesh, 2011). According to the statistics provided by the end of 1385 (2006), there have been about 1,046 active agricultural production cooperatives in the country, covering a total of 4,963 villages with a population of about 278,362 people. There are 174 agricultural cooperatives in the city of Shirvan-Chrdavol and Halylan from which 102 cooperatives (751 members) are active, 46 cooperatives are inactive and 26 cooperatives are in their establishment stage (Cooperative Department of Shirvan-Chrdavol Township, 2011. Many Researchers have point to the neglect of cooperative system in the national economy, as the most important harming factor that may eventually bring the system to crash. As a matter of fact, many of the production cooperatives in our country lack the features of actual cooperatives, because most of them have been established by the government; in fact they are unreal or semicooperatives (Kildbary et al., 2011). Most of agricultural cooperatives have failed in achieving a sustainable performance due to gradual deterioration of their members' essential role and failure in improving management performance in accordance with the economic changes. Also according to official report of Ministry of Cooperatives in the year 1385, there were some 129 thousand cooperative in the country of which only 92 thousand cooperatives were active and the rest were on the verge of dissolution. Also in the city of Shirvan-Chrdavol something about $45 \%$ of the agricultural sector cooperatives are on the verge of closure or sale Department of Cooperatives of Ilam Province, 2010. To solve such major problems in the country is real and not symbolic participation in public policies and investments to cooperatives and other organizations providing social, political and cultural role of national development objectives assigned to the. In fact, the agricultural sector of Iran in general and Shirvan-Chrdavol Township in particular are in need of such associations. The fundamental problem of this research is studying the reasons why the ShirvanChardavol farmers have little motivation for participating in agricultural production cooperatives and why they are more interested in individual exploiting system. To examine the fundamental problem of this study, the following questions have been raised: Why Shirvan-Chrdavol township farmers have little participation in agricultural cooperatives? What factors can be effective in encouraging them to more constructively participate in such cooperatives?

Arayesh and Mammi (2010) in considering the factors influencing the participation of members of agricultural cooperatives in decisions concerning the management of agricultural cooperatives in Tehran concluded that there is significant and positive relationship between the member's age, education level, number of shares (in cooperative) and the resulting profits from the one hand and the level of their participation in decision-making of the cooperative company from the other. Saharkhiz (2009) investigated the mechanisms of attracting popular participation in the cooperative companies-especially multi-purpose cooperatives-from the perspective of cooperative sector and the relevant organizations' executive directors and showed that in respondents' opinion, from the various factors, the government's supportive policies regarding the cooperative sector (especially in multi-purpose cooperative companies framework) played the most important and influential role in attracting the effective popular participation and believed that promoting the scientific and technical capabilities of the cooperatives' managers and increasing the people's awareness of the cooperative sector was the next crucial factor in this regard (Arayesh and Hosseini, 2010). Participation by natives in local programm enables communities to have control over resources. Increase engagement and decision making and improves their general wellbeing. When individuals are empowered as a consequence of active participation (Lyndon et al., 2011). To have the participants and researchers Identify the key Elements and indicators of health issues the communities feel are most immportant to their ways of life (Chantarasombat, 2011). Vahidzadeh (2004) argues that the dominant cause of the failure of cooperatives can be found in three categories of poor management, lack of organizational discipline and weakness in financial vigor. The most significant weak point of the production cooperatives lies in their organizational structure and managerial issues. Khodashahri (2009) in a study entitled" Participation effects of fishermen members of Gilan province cooperatives in economic performance of the cooperatives" concluded that there is a significant relationship between the literacy, membership history, amount of shares, knowledge of 
cooperative principles and regulations, satisfaction from the cooperative, attending the training-extension courses and ultimately economic performance from the one hand and participation level from the other.

Flick (2009) considers the following factors as the main challenges and risks among the cooperative members, affecting the performance of the cooperatives.

Lack of motivation among the staff, top-down planning, lack of funds and delayed allocation time, lack of educational facilities in the extension centers, low-literacy and illiteracy of majority of the farmers, lack of skilled manpower, the farmers' distrust of some experts, non-institutionalization of people's participation, extension staff involvement in administrative works, lack of proper planning in the network use of the popular forces, the lack of updated information of extension staff, lack of refresher courses and lack of extension law in the extension system of the country. Jenson (1990) in a study found that experienced farmers have expressed the "quality services" as the criteria for choosing between membership and non-membership in a cooperative. Steinhoff, 2008 studied the use of Internet in consumption cooperatives. Nowadays the Internet plays an important role in members' participation in many countries. For example, the PAL system was established in Japan in 2001 and in 2007, the number of subscribers reached to more than 2.2 million members. In total, about 0.35 of total cooperative members of Japan are also members of the PAL systems Steinhoff, 2008.

General objective of this study is identifying the factors affecting the participation of Shirvan-Chrdavol township agricultural cooperatives' members together with the following specific objectives:

- Studying the relationship between the sociocultural, economical, political, educationalextensional, managerial, psychological and informational-communicational factors with the variable of agricultural cooperatives' members' participation

- Considering the collective influence of independent variables on the dependent variable variance (participation of members of agricultural cooperatives)

\section{MATERIALS AND METHODS}

This study is of applied, survey and casual comparative research type. Data accumulation has been performed based on the Documentary-library and field study method. The main tool for gathering data was questionnaire and the estatistical society of the research included 751 active members of Shirvan-Chardavol township's agricultural cooperatives, among which 256 people were selected as samples using Morgan samplevolume table, based on classified proportional random sampling method; the number of samples were then increased to 260 samples for higher validity. Validity of the questionnaire was confirmed by a group of university professors and members of Research Council of Ilam Province Department of Cooperatives; Also for the purpose of determining the reliability of the questionnaire, a pilot test was given to a sample group of 25 cooperative members out of the sample society range and the Kronbach alfa coefficient of 0.80 was obtained for different parts of the questionnaire after data processing through using SPSS software. The independent variables of the research included the personal-professional features, socio-cultural features, economical features, educational-extensional factors, managerial factors, psychological features, politicalgovernmental factors, communicational-informational factors and awareness about advantages of participation in agricultural cooperatives; the dependent variable of the research was agricultural cooperatives' members' level of participation.

\section{RESULTS AND DISCUSSION}

In this study, after reading previous research related to research, collect data from the survey instrument was reviewed. In the primary sector, demographic characteristics of the statistical community have been discussed. Then, to examine relationships between variables was investigated using the Spearman correlation coefficient. So, At this stage for evaluating the collective role of the independent variables on the dependent variable, stepwise multiple regression analysis has been used. In stepwise method, the most powerful variables introduced into the regression equation one at a time and this continues until the significance test error reaches to 5\%. After considering the relationships between the research variables and the main variable, four variables were introduced into the multiple regression equation. In the linear regression section, linear regression assumptions were tested. To checking independence of statistical errors have been used durbin Watson test. Because in this study, its value is equal to 2.04 obtained, therefore, be accepted no correlation between Statistical errors. To checking normality of dependence variable was used histogram chart. To investigate the correlation between independent variables is used multi co linearity test. To done this test, is calculated coefficients, tolerance and variance inflation factor. 
Am. J. Agri. \& Biol. Sci., 6 (4): 560-566, 2011

Table 1: Relationship between the research variables (Spearman correlation coefficient)

\begin{tabular}{llll}
\hline $\mathrm{P}$ & $\rho$ & Second variable & First variable \\
\hline $0 / 0.1$ & $* 160.00$ & Agricultural cooperatives' members' participation & Age \\
$0 / 000$ & $* * 0.23$ & Agricultural cooperatives' members' participation & Background membership history \\
0.002 & $* * 0.14$ & Agricultural cooperatives' members' participation & Farmland area \\
0.001 & $* * 0.20$ & Agricultural cooperatives' members' participation & Annual income \\
$0 / 000$ & $* 0.30$ & Agricultural cooperatives' members' participation & Socio-cultural features \\
$0 / 000$ & $* * 0.31$ & Agricultural cooperatives' members' participation & Economical features \\
$0 / 000$ & $* * 0.23$ & Agricultural cooperatives' members' participation & Educational-extensional features \\
$0 / 000$ & $* * 0.24$ & Agricultural cooperatives' members' participation & Managerial factors \\
$0 / 000$ & $* * 0.36$ & Agricultural cooperatives' members' participation & Psychological features \\
$0 / 000$ & $* * 0.53$ & Agricultural cooperatives' members' participation & Political factors \\
$0 / 000$ & $* * 0.35$ & Agricultural cooperatives' members' participation & Communicational-informational factors \\
\hline
\end{tabular}

Table 2: Summary of the regression model

\begin{tabular}{|c|c|c|c|c|c|c|c|c|}
\hline Durbin- Watson & $\begin{array}{l}\mathrm{F} \text { variations } \\
\text { significance level }\end{array}$ & Variations & $\begin{array}{l}\mathrm{R}^{2} \\
\text { changes }\end{array}$ & $\begin{array}{l}\text { Approximation } \\
\text { standard deviation }\end{array}$ & Adjusted $\mathrm{R}^{2}$ & $\mathrm{R}^{2}$ & $\mathrm{R}$ & Model \\
\hline \multirow[t]{4}{*}{2.04} & 0.000 & 165.20 & 0.427 & 4.16 & 0.424 & 0.427 & 0.65 & 1 \\
\hline & 0.000 & 117.92 & 0.199 & 3.36 & 0.623 & 0.626 & 0.79 & 2 \\
\hline & 0.000 & 18.14 & 0.028 & 3.24 & 0.650 & 0.655 & 0.80 & 3 \\
\hline & 0.012 & 6.35 & 0.010 & 3.20 & 0.658 & 0.644 & 0.81 & 5 \\
\hline
\end{tabular}

Demographical features of the statistical society: Investigation showed that the mean age of the individuals under study has been 45 years while the age class of 41-50 years old samples had the highest frequency. About $94 \%$ of the members were men and about $6 \%$ of them were women, indicating that women do not have an active role in agricultural cooperatives of the region. Also $23.1 \%$ of the members were high school graduates, $14.9 \%$ were above high school graduates, $14.5 \%$ were university graduates and higher, $13.3 \%$ had some middle school education, 9\% were primary school educated and $8.6 \%$ had some high school education. Moreover, $16.5 \%$ of the samples were illiterate, indicating that half of the members were illiterate or uneducated; this notifies the necessity for considering the required facilities for their literacy by the relevant organs. Studies showed that most of the under study people's profession was animal husbandry and farming and fewer were self-employed, employees and workers. The results showed that the average background years of membership in agricultural cooperatives were about 12 years. Most of the floors 11-15 years membership in the cooperative, while those with 11-15 years membership background had the highest frequency; this represents that the members are experienced and relatively skilled in working with agricultural cooperatives. The average area of agricultural land in this study was obtained as equal to 6.5 acres and more than half of the people possessed between one and five hectares of farmland. Studies on members' annual income from farming occupation show that about $37.8 \%$ of the total members under study have an annual income of equal to or less than 4,000,001 Rials. Also $34.5 \%$ of the members under study have an annual income somewhere between 40,000,001 and 80,000,000 Rials from farming occupation. In most cases, that is $67.1 \%$ of the under study samples enjoyed private property ownership and the rest exploited their farmlands through renting, shareholding, endowed lands, nationalized and collective lands. Study showed that the members' awareness and knowledge level about the benefits of participation in agricultural cooperatives has been moderate upward.

Study of correlation for testing the research relationships hypotheses: In the present study, the Spearman correlation coefficient was used for assessing the relationship between the research variables in accordance with the employed scales (Table 1-3).

Correlation coefficient results showed that there is significant relationship between the variables like age, background membership in cooperatives, the members' farmland areas, annual income, socio-cultural features, economical features, educational-extensional features, managerial factors, psychological features, political factors and communicational-informational factors from the one hand and the dependent variable of agricultural cooperatives' members' participation from the other.

Multiple regression: At this stage for evaluating the collective role of the independent variables on the dependent variable, stepwise multiple regression analysis has been used. In stepwise method, the most powerful variables introduced into the regression equation one at a time and this continues until the significance test error reaches to $5 \%$. After considering the relationships between the research variables and the main variable, four variables were introduced into the multiple regression equation, respectively mentioned as follows. 
Am. J. Agri. \& Biol. Sci., 6 (4): 560-566, 2011

Table 3: Coefficients of the variables introduced into regression equation

\begin{tabular}{|c|c|c|c|c|c|c|c|c|}
\hline \multicolumn{9}{|l|}{ Co-linearity test } \\
\hline \multicolumn{9}{|l|}{ Variance } \\
\hline Inflation factor & Tolerance & Sig & $\mathrm{T}$ & Beta & B Standard error & $\mathrm{B}$ & Variable & Model \\
\hline \multirow[t]{2}{*}{1.000} & 1.00 & 0.000 & 12.85 & 0.653 & 0.050 & 0.640 & Political factors & 1 \\
\hline & & 0.000 & 10.79 & & 0.980 & 10.570 & Constant & \\
\hline 1.000 & 0.98 & 0.000 & 12.86 & 0.545 & 0.040 & 0.530 & Political factors & \\
\hline \multirow[t]{2}{*}{1.000} & 1.00 & 0.000 & 10.85 & 0.460 & 0.030 & 0.320 & Economical factors & 2 \\
\hline & & 0.001 & 3.370 & & 1.020 & 3.460 & Constant & \\
\hline 1.000 & 0.99 & 0.000 & 12.45 & 0.515 & 0.040 & 0.500 & Political factors & \\
\hline 1.000 & 1.00 & 0.000 & 7.210 & 0.349 & 0.340 & 0.240 & Economical factors & 3 \\
\hline \multirow[t]{2}{*}{1.000} & 1.00 & 0.000 & 4.260 & 0.208 & 0.031 & 0.130 & Managerial factors & \\
\hline & & 0.021 & 2.310 & & 1.020 & 0.237 & Constant & \\
\hline 1.000 & 0.99 & 0.000 & 12.26 & 0.504 & 0.410 & 0.490 & Political factors & \\
\hline 1.000 & 1.00 & 0.000 & 4.870 & 0.274 & 0.040 & 0.190 & Economical factors & \\
\hline 1.000 & 1.00 & 0.000 & 3.470 & 0.174 & 0.032 & 0.112 & Managerial factors & 4 \\
\hline \multirow[t]{2}{*}{1.000} & 1.00 & 0.012 & 2.520 & 0.142 & 0.043 & 0.110 & Social factors & \\
\hline & & 0.089 & 1.710 & & 1.030 & 1.770 & Constant & \\
\hline
\end{tabular}

Step 1: At this stage, the first variable, that is political factors was introduced into the regression equation, meaning that this variable has had the greatest effect; the correlation coefficient, coefficient of determination and the adjusted determination coefficient were calculated as equal to $r=0.65, R^{2}=0.42$ and $R^{2}=$ 0.42 respectively. On the other hand, the value of $\mathrm{f}$ obtained from variation analysis is significant at $\mathrm{p}=$ 0.000 level; so it can be said that political factors' variable alone contributes to about $42 \%$ of variations in the dependent variable of agricultural cooperatives members' participation. The regression equation of the first step is:

$y=0.64 x_{1}+10.57$

Step 2: At this stage, after the political factors, the economic factors were entered into the equation; in this stage the correlation coefficient, coefficient of determination and the adjusted determination coefficient were calculated as equal to $\mathrm{r}=0.79, \mathrm{R}^{2}=$ 0.62 and $R^{2}=0.62$ respectively. Furthermore, the $f$ value obtained from variation analysis is significant at $p$ $=0.000$ level; based on the findings, the political and economical factors' variables contribute to $62 \%$ of variations in the dependent variable. The regression equation of the second step is:

$y=0.53 x_{1}+0.32 x_{2}+3.46$

Step 3: At this stage, after introducing the political and economic factors, the managerial factors variable was introduced into the multivariate regression equation; in this stage the correlation coefficient, coefficient of determination and the adjusted determination coefficient were calculated as equal to $\mathrm{r}=0.80, \mathrm{R}^{2}=$ 0.65 and $R^{2}=0.65$ respectively. Also, the obtained $\mathrm{f}$ value is significant at $\mathrm{p}=0.000$ level; considering the obtained coefficient of determination, it can be said that the political, economical and managerial factors' variables contribute to $65 \%$ of variations in the dependent variable. The regression equation of the third step is:

$\mathrm{y}=0.50 \mathrm{x}_{1}+0.24 \mathrm{x}_{2}+0.13 \mathrm{x}_{3}+2.37$

Step 4: At this stage, after the previous variables, the socio-cultural factors variable was introduced into the multivariate regression equation; in this stage the correlation coefficient, coefficient of determination and the adjusted determination coefficient were calculated as equal to $r=0.81, R^{2}=0.66$ and $R^{2}=0.65$ respectively. Also, the obtained $\mathrm{f}$ value is significant at $\mathrm{p}=0.000$ level; the regression equation of the forth step is:

$y=0.49 x_{1}+0.19 x_{2}+0.112 x_{3}+0.110 x_{4}+1.77$

On the whole, the multiple regression analysis results showed that varriables like political, economic, managerial and social factors have positive effect on the dependent variable of agricultural cooperatives' members' participation, describing $65 \%$ of the changes of the mentioned dependent variable.

\section{CONCLUSION}

Research conducted by Sheikhi (2009) showed that the members' age has impact on their participation in agricultural cooperatives; this finding is confirmed by the present study. The correlation coefficient results of the study showed that there is a significant relationship between the two variables of membership history and participation level. These results are consistent with the research findings of Khodashahri (2009). Research conducted by Sam-Aram (2005) showed that the 
amount of agricultural land has positive effect on the participation of members of cooperatives; this was confirmed by the present study. The correlation coefficient results showed that there is a significant relationship between the two variables of income and level of participation of agricultural cooperatives' members. This finding is consistent with findings of the research conducted by Scrimgeour et al. (2006). The correlation coefficient results showed that there is a significant relationship between the two variables of socio-cultural factors and level of participation of agricultural cooperatives' members. This finding is consistent with findings of the studies conducted by some researchers as Aghajani (2008) and Scrimgeour et al. (2006). Studies undertaken and Vahidzadeh (2004) showed that the members' economical features have direct impact on their participation in agricultural cooperatives; this finding is confirmed by the present study. The correlation coefficient results showed that there is a significant relationship between the two variables of educational-extensional factors and the level of participation of agricultural cooperatives' members. This finding is consistent with findings of the studies conducted by SafariShali (2010); Aghajani (2008) and Flick (2009). Studies undertaken by SafariShali (2010) and Flick (2009) showed that the managerial factors have direct impact on the level of participation of the agricultural cooperatives' members; this finding is consistent with the findings of the present study. Studies undertaken by Aghajani (2008) and Maghsoudi et al. (2009) showed that the cooperatives' members' psychological features have impact on their participation in agricultural cooperatives' activities; this finding has been confirmed by the present study. The correlation coefficient results showed that there is a significant relationship between the two variables of political-governmental factors and the level of participation of agricultural cooperatives' members. This finding is consistent with findings of the studies conducted by Saharkhiz (2009). The research findings showed that there is a significant relationship between the two variables of communicational-informational factors and the level of participation of agricultural cooperatives' members. This finding is consistent with findings of the studies conducted by Flick (2009).

Given the correlation and regression analyses results and for the purpose of increasing the participation of members of agricultural cooperatives, the following recommendations are made:

- Increasing the education level of cooperative members and the using their experiences concerning agricultural cooperatives
- Raising the sense of responsibility of members and increasing the self-confidence of members of agricultural cooperatives through holding various seminars, conferences and meetings

- Creating interest among the members for more participation in agricultural cooperatives affairs

- Developing small industries and workshops by cooperatives to increase the employment opportunities

- Planning for increasing the income and profits of members of agricultural production cooperatives

- Governmental support of agricultural cooperatives, so that the members can benefit from supportive facilities as incentive for participation

- Providing extension trips for the farmers to visit successful cooperatives

- Distributing extensional publications and brochures among the cooperatives' members

- Providing the necessary conditions for lasting stability of the management of agricultural cooperatives

- Employing specialized and experienced managers in the field of agricultural cooperatives

- Motivate the managers for better participation of the cooperative members

- Using electronic means (Computers, Internet, Intranet)

- Using visual media (videos)

- Using mass media (radio and television)

\section{REFERENCES}

Aghajani, V.M., 2008. Study and assessment of activities of rural production cooperatives in Isfahan province (1973-1993). M.A. Thesis. College of Agriculture, Isfahan University of Technology.

Arayesh, B. and S. Mammi, 2010. Prioritization role of psychological factors in the process of popular participation groups to preserve, revival, develop and using natural resources (Case study: Iran. Ilam Province). Procedia-Soc. Behav. Sci., 5: 174-177. DOI: $10.1016 /$ j.sbspro.2010.07.068

Arayesh, B. and S.J. Hosseini, 2010. Regression analysis of effective factor on people participation in protecting, revitalizing, developing and using renewable natural resources in ilam province from the view of users. Am. J. Agric. Biol. Sci., 5: 228234. DOI: 10.3844/ajabssp.2010.228.234

Arayesh, B., 2011. An Analysis of People's participation Barriers in Protection and Regeneration of Forests and Pastures: The application of factor analysis techniques (A Case Study, Ilam, Iran). Trends Adv. Sci. Eng., 2: 2-6. 
Chantarasombat, C., 2011. Developing community health conditions for happiness, phase 1. J. Soc. Sci., 7: 627-631. DOI: 10.3844/jssp.2011.627.631

Flick, U., 2009. An Introduction to Qualitative Research. 1st Edn., SAGE Publications Ltd, London, ISBN-10: 1847873243, pp: 528.

Jenson, K., 1990. Factors associated with the selection of cooperative Vs. proprietary handlers of milk in tennessee. J. Agric. Cooper.

Khodashahri, H.A.S., 2009. A study of the fishermen participation impact on economic performance of the Gilan province cooperatives. Taavon J. Cooperatives.

Kildbary, H.R., M.R. Dizgah and F.R. Gorabe, 2011. Investigating relationship between empowerment and organizational Commitment in public sector of Guilan province. Trends Adv. Sci. Eng., 2: 42-48.

Lyndon, N., R. Moorthy, A.C. Er and S. Selvaduri, 2011. Native understanding of participation and empowerment in community development. J. Soc. Sci., 7: 643-648. DOI: 10.3844/jssp.2011.643.648

Maghsoudi, A., R.V. Torshizi and A.S. Jahanshahi, 2009. Estimates of (co)variance components for productive and composite reproductive traits in Iranian Cashmere goats. Livestock Science, 126: 162-167. DOI: 10.1016/j.livsci.2009.06.016

Mousaei, M. and B. Arayesh, 2011. Effective factors to rural youths attitude to engagement in agriculture: A case study of Kohgiluye and Boyerahmad province. Sci. Res. Essay, 6: 2426-2430.

Peterson, D.K., 2004. Benefits of participation in corporate volunteer programs: Employees' perceptions. Personnel Rev., 33: 615-627. DOI: $10.1108 / 00483480410561510$
SafariShali, R., 2010. A survey of the activities and performance of poultry agricultural cooperatives of Tehran Province. M.A. Thesis, College of Agriculture, Isfahan University of Technology.

Saharkhiz, E., 2009. A study of the ways of attracting the people participation in creating cooperativesparticularly Multi-purpose cooperatives-from the viewpoint of administrative managers related to cooperative sector. Hamedan Province Department of Cooperatives.

Sam-Aram, E., 2005. Participation causes of member of Ghaleno village cooperative. Varamin Township Cooperation Department.

Scrimgeour, F., A. McDermott, C. Saunders, N.M. Shadbolt and G. Sheath, 2006. New Zealand agribusiness success: An approach to exploring the role of strategy, structure and conduct on firm performance. Proceedings of the to New Zealand Agricultural and Resource Economics Society (Inc.) Conference, Aug. 24-25, Nelson, New Zealand, pp: 25-27.

Sheikhi, M., 2009. A study of the factors influencing the member participation of agricultural cooperatives in decision making relative to the management of Tehran province agricultural cooperatives. MA thesis, Tehran University

Vahidzadeh, A., 2004. Pathology of management in production cooperatives. Taavon J. Cooperatives. 